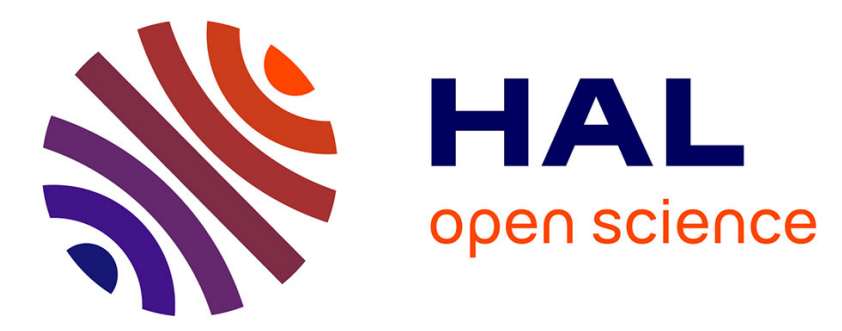

\title{
Virtual-Sensor-Based Maximum-Likelihood Voting Approach for Fault-Tolerant Control of Electric Vehicle Powertrains
}

Bekheira Tabbache, Mohamed Benbouzid, Abdelaziz Kheloui, Jean-Matthieu Bourgeot

\section{To cite this version:}

Bekheira Tabbache, Mohamed Benbouzid, Abdelaziz Kheloui, Jean-Matthieu Bourgeot. VirtualSensor-Based Maximum-Likelihood Voting Approach for Fault-Tolerant Control of Electric Vehicle Powertrains. IEEE Transactions on Vehicular Technology, 2013, 62 (3), pp.1075-1083. 10.1109/TVT.2012.2230200 . hal-00802973

\section{HAL Id: hal-00802973 https://hal.science/hal-00802973}

Submitted on 20 Mar 2013

HAL is a multi-disciplinary open access archive for the deposit and dissemination of scientific research documents, whether they are published or not. The documents may come from teaching and research institutions in France or abroad, or from public or private research centers.
L'archive ouverte pluridisciplinaire HAL, est destinée au dépôt et à la diffusion de documents scientifiques de niveau recherche, publiés ou non, émanant des établissements d'enseignement et de recherche français ou étrangers, des laboratoires publics ou privés. 


\title{
Virtual-Sensor-Based Maximum-Likelihood Voting Approach for Fault-Tolerant Control of Electric Vehicle Powertrains
}

\author{
Bekheïra Tabbache, Mohamed El Hachemi Benbouzid, Senior Member, IEEE, \\ Abdelaziz Kheloui, and Jean-Matthieu Bourgeot
}

\begin{abstract}
This paper describes a sensor fault-tolerant control (FTC) for electric-vehicle (EV) powertrains. The proposed strategy deals with speed sensor failure detection and isolation within a reconfigurable induction-motor direct torque control (DTC) scheme. To increase the vehicle powertrain reliability regarding speed sensor failures, a maximum-likelihood voting (MLV) algorithm is adopted. It uses two virtual sensors [extended Kalman filter (EKF) and a Luenberger observer (LO)] and a speed sensor. Experiments on an induction-motor drive and simulations on an EV are carried out using a European urban and extraurban driving cycle to show that the proposed sensor FTC approach is effective and provides a simple configuration with high performance in terms of speed and torque responses.
\end{abstract}

Index Terms-Electric vehicle (EV), extended Kalman filter (EKF), fault-tolerant control (FTC), induction motor, Luenberger observer (LO), maximum-likelihood voting (MLV), speed sensor failure.

\section{NOMENCLATURE}

EV Electric vehicle.

FTC Fault-tolerant control.

EKF Extended Kalman filter.

LO Luenberger observer.

MLV Maximum-likelihood voting.

$v \quad$ Vehicle speed.

$F_{w} \quad$ Road load.

$F_{\text {ro }} \quad$ Rolling resistance force.

$F_{\mathrm{sf}} \quad$ Stokes or viscous friction force.

$F_{\text {ad }} \quad$ Aerodynamic drag force.

$F_{\text {cr }} \quad$ Climbing and downgrade resistance force.

$P_{v} \quad$ Vehicle driving power.

$J \quad$ Total inertia (rotor and load).

Manuscript received February 3, 2012; revised June 19, 2012, October 3, 2012, and November 19, 2012; accepted November 20, 2012. Date of publication November 27, 2012; date of current version March 13, 2013. The review of this paper was coordinated by Dr. C. H. Mi.

B. Tabbache is with the University of Brest, EA 4325 LBMS, 29238 Brest, France, and also with the Ecole Militaire Polytechnique, 16111 Algiers, Algeria.

M. E. H. Benbouzid is with the University of Brest, EA 4325 LBMS, 29238 Brest Cedex 03, France (e-mail: Mohamed.Benbouzid@univ-brest.fr).

A. Kheloui is with the Ecole Militaire Polytechnique, 16111 Algiers, Algeria.

J.-M. Bourgeot is with the Ecole Nationale d'Ingénieurs de Brest, EA 4325 LBMS, 29280 Plouzané, France.

Color versions of one or more of the figures in this paper are available online at http://ieeexplore.ieee.org.

Digital Object Identifier 10.1109/TVT.2012.2230200

\author{
$\omega_{m} \quad$ Electric motor mechanical speed. \\ $T_{B} \quad$ Load torque accounting for friction and windage. \\ $T_{L} \quad$ Load torque. \\ $T_{m} \quad$ Electric motor torque. \\ $i \quad$ Transmission ratio. \\ $\eta_{t} \quad$ Transmission efficiency. \\ $R \quad$ Wheel radius. \\ $s,(r) \quad$ Stator (rotor) index. \\ $\alpha, \beta \quad$ Synchronous reference frame index. \\ $\operatorname{est}(\wedge) \quad$ Estimated quantity. \\ * Reference quantity. \\ $V(I) \quad$ Voltage (current). \\ $\lambda \quad$ Flux. \\ $\omega_{r} \quad$ Rotor electric speed. \\ $T_{\mathrm{em}} \quad$ Motor torque. \\ $R \quad$ Resistance. \\ $L\left(L_{m}\right) \quad$ Inductance (Magnetizing inductance). \\ $\sigma \quad$ Leakage coefficient, where $\sigma=1-L_{m}^{2} / L_{s} L_{r}$. \\ $T_{r} \quad$ Rotor time constant $\left(T_{r}=L_{r} / R_{r}\right)$. \\ $T_{s} \quad$ Stator time constant $\left(T_{s}=L_{s} / R_{s}\right)$. \\ $T \quad$ Sampling time. \\ $p \quad$ pole-pair number.
}

\section{INTRODUCTION}

$\mathbf{T}$ $\mathrm{O}$ increase the reliability and the continuous operation of electromechanical systems [1]-[3], interest in fault tolerance has grown. Indeed, extensive research has been conducted toward fault-tolerant alternating-current motor drives in industrial applications [4]-[10].

In the automotive context, the dependence of electric and hybrid vehicles on electronic devices is heightening concerns over fault tolerance due to availability issues [11]-[14]. In the EV case, the propulsion control depends on the availability and the quality of sensor measurements. The required sensors are current, voltage, and speed sensors. These components are usually subjected to errors such as noise, offset, drift, and disconnections [3]. These failures obviously lead to overall EV performance deterioration. To improve the reliability of the electric drive, it is therefore compulsory to have a sensor fault detection and isolation system. Thereafter, reconfiguration should be achieved with equivalent observed signals. This will allow EV propulsion fault-tolerant operation [15]-[17]. 


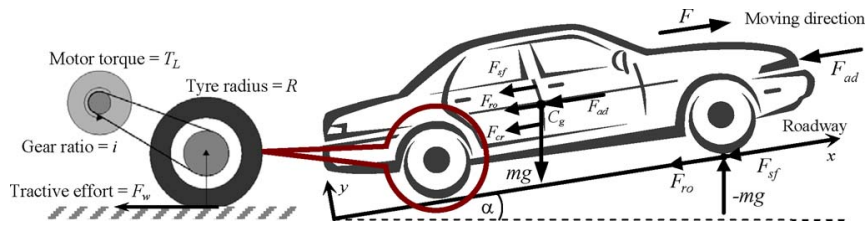

Fig. 1. Elementary forces acting on a vehicle.

In this context, this paper proposes a fault-tolerant direct torque control (DTC) strategy in case of speed sensor failure intended for EVs using an induction-motor-based powertrain [18]. For that purpose, a specific speed sensor failure detection is achieved, and an MLV algorithm is adopted and implemented for speed information acquisition [6], [19]. This algorithm uses two virtual sensors (the EKF and the LO) and a speed sensor. Experiments on an induction-motor drive and simulations on an EV are carried out using a European urban and extraurban driving cycle to show that the proposed sensor FTC approach is effective and provides a simple configuration with high performance in term of speed and torque responses.

The major contribution of this paper is as follows. It proposes a specific speed sensor FTC scheme for EV powertrains. This scheme uses a DTC for the induction-motor drive and handles the EV dynamics. The FTC scheme is based on the MLV algorithm that uses the speed sensor information and analytical redundancy (virtual sensors that are based on the EKF and the LOs). These observers have been specifically adopted due to their ability to fit the EV entire speed range.

The remaining parts of this paper are organized as follows.

- Section II briefly describes the elementary forces acting on a vehicle and how they will be handled (in the load torque).

- Section III briefly describes the global configuration of a DTC scheme and shows how the EV aerodynamics is taken into account to generate the induction-motor load torque.

- Section IV presents and justifies the adopted speed observers that will be used by the voting algorithm.

- Section V deals with the adopted speed sensor FTC strategy. It particularly describes and justifies the use of the MLV algorithm.

- Sections VI and VII, respectively, describe the carriedout simulations and experiments to assess the proposed speed sensor FTC strategy performances.

\section{Electric Vehicle Modeling And DYNAMICS BRIEFLY}

The proposed sensor FTC strategy takes into account the EV aerodynamics and is not applied to the sole induction motor. The vehicle model is based on mechanics and aerodynamics principles (see Fig. 1) [20].

The road load is then given by

$$
F_{w}=F_{\text {ro }}+F_{\text {sf }}+F_{\text {ad }}+F_{\text {cr }}
$$

The power required to drive the $\mathrm{EV}$ at a speed $v$ has to compensate the road load $F_{w}$, i.e.,

$$
P_{v}=v F_{w}
$$

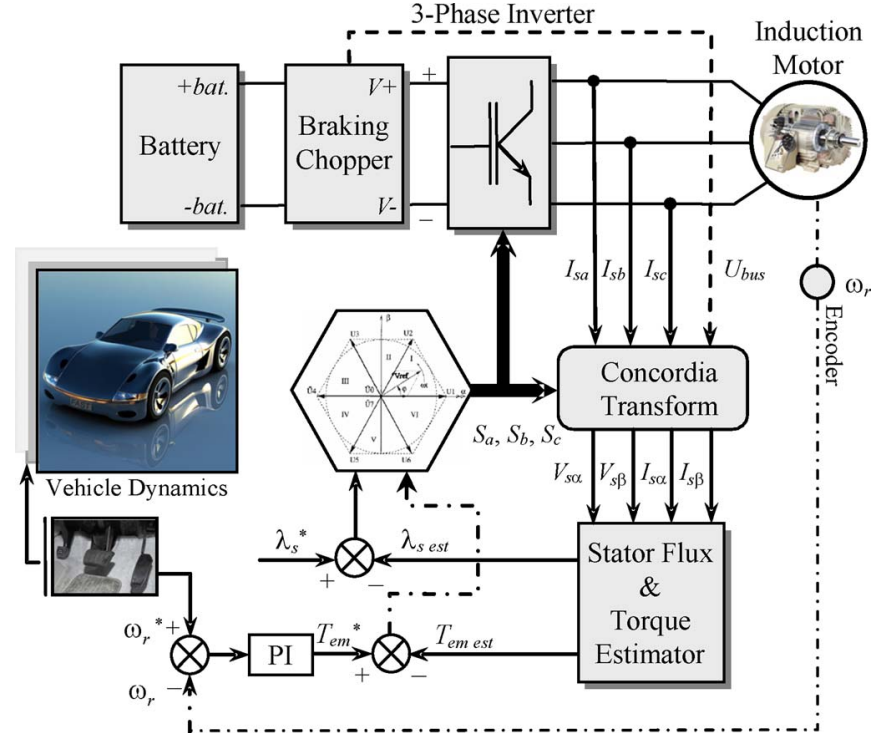

Fig. 2. DTC block diagram.

The mechanical equation (in the motor referential) used to describe each wheel drive is expressed by

$$
J \frac{d \omega_{m}}{d t}+T_{B}+T_{L}=T_{m} .
$$

The following equation is derived due to the use of a reduction gear:

$$
\left\{\begin{array}{l}
\omega_{\text {Wheel }}=\frac{\omega_{m}}{i} \\
T_{\text {Wheel }}=T_{m} i \eta_{t}
\end{array} .\right.
$$

The load torque in the motor referential is then given by

$$
T_{L}=\frac{T_{\text {LWheel }}}{i}=\frac{R}{i} F_{\omega} .
$$

\section{Direct Torque Control Briefly}

The DTC basic idea is to calculate flux and torque instantaneous values only from the stator variables. In the proposed strategy, flux, torque, and speed are estimated by the EKF and the LO. The motor controller input is the reference speed, which is directly applied by the driver on the EV pedal. The control is carried out by hysteresis comparators and a switching logic table selecting the appropriate voltage inverter switching configurations [21].

Fig. 2 gives the global configuration of a DTC scheme and also shows how the EV dynamics is taken into account to generate the induction-motor load torque. The proposed global DTC approach uses a speed sensor. This may be confusing as DTC is a sensorless control approach. In our case, as clearly shown in Fig. 2, the speed sensor is used for speed control allowing the generation of the necessary torque reference for the DTC. This approach is adopted to improve the DTC performances [22].

\section{SPEed ObSERVERS}

Sensorless control of induction-motor drives is still receiving wide attention. The main reason is that the speed sensor spoils 
the ruggedness and simplicity of induction motors. In a hostile environment, as is the case of automotive applications, speed sensors cannot even be mounted [23]. For that purpose, several works in term of eliminating the speed sensor at the motor shaft without deteriorating the drive dynamic performance have been carried out [24], [25].

For the proposed speed sensor FTC approach, the EKF and the LO (adaptive one) are adopted as speed observers [26]. Indeed, they will be used to determine the induction-motor speed and generate the residuals used by the MLV algorithm.

\section{A. $E K F$}

The Kalman filter is a special class of a linear observer (deterministic type) derived to meet a particular optimality stochastic condition. The Kalman filter has two forms: basic and extended. The EKF can be used for nonlinear systems where the plant model is extended by extra variables, in our case, by the mechanical speed [27].

In the induction-motor drive, the Kalman filter is used to obtain unmeasured state variables (rotor speed $\omega_{r}$, rotor flux vector components $\lambda_{r \alpha}$ and $\lambda_{r \beta}$ ) using the measured state variables (stator current $I_{s}$ and voltage components $V_{s}$ in Concordia frame $\alpha-\beta$ ). Moreover, it takes into account the model and the measurement noise.

The induction-motor state model used by the EKF is developed in the stationary reference frame and summarized by [28]

$$
\begin{gathered}
\frac{d}{d t}\left[\begin{array}{l}
I_{s \alpha} \\
I_{s \beta} \\
\lambda_{r \alpha} \\
\lambda_{r \beta} \\
\omega_{r}
\end{array}\right]=\left[\begin{array}{ccccc}
-\frac{K_{R}}{K_{L}} & 0 & \frac{L_{m} R_{r}}{L_{r}^{2} K_{1}} & \frac{L_{m} \omega_{r}}{L_{r} K_{L}} & 0 \\
0 & -\frac{K_{R}}{K_{L}} & \frac{L_{m} \omega_{r}}{L_{r} K_{L}} & \frac{L_{m} R_{r}}{L_{r}^{2} K_{1}} & 0 \\
\frac{L_{m}}{T_{r}} & 0 & -\frac{1}{T_{r}} & -\omega_{r} & 0 \\
0 & \frac{L_{m}}{T_{r}} & \omega_{r} & -\frac{1}{T_{r}} & 0 \\
0 & 0 & 0 & 0 & 1
\end{array}\right]\left[\begin{array}{c}
I_{s \alpha} \\
I_{s \beta} \\
\lambda_{r \alpha} \\
\lambda_{r \beta} \\
\omega_{r}
\end{array}\right] \\
+\frac{1}{K_{L}}\left[\begin{array}{ll}
1 & 0 \\
0 & 1 \\
0 & 0 \\
0 & 0 \\
0 & 0
\end{array}\right]\left[\begin{array}{l}
V_{s \alpha} \\
V_{s \beta}
\end{array}\right] \text { with } \frac{K_{L}}{K_{R}}=\left(\frac{R_{s}}{\sigma L_{s}}+\frac{1-\sigma}{\sigma T_{r}}\right) .
\end{gathered}
$$

The implementation of the Kalman filter is based on a recursive algorithm minimizing the error variance between the real variable and its estimate.

Let us consider a linear stochastic system whose discrete state model is given by

$$
\left\{\begin{array}{l}
x(k+1)=A x(k)+B u(k)+w(k) \\
y(k+1)=C x(k)+v(k)
\end{array}\right.
$$

where $w(k)$ represents the disturbances vector applied to the system inputs. It also represents modeling uncertainties; $v(k)$ corresponds to system output measurement noise. It is supposed that the random signals $v(k)$ and $w(k)$ are Gaussian noise that is not correlated and with a null average value. They are characterized by covariance matrices $Q$ and $R$, respectively, which are symmetrical and positive definite. The initial state vector $x_{0}$ is also a random variable with covariance matrix $P_{0}$ and average value $\bar{x}_{0}$.

The Kalman filter recursive algorithm is shown in Fig. 3. For an induction motor, the Kalman filter must be used in

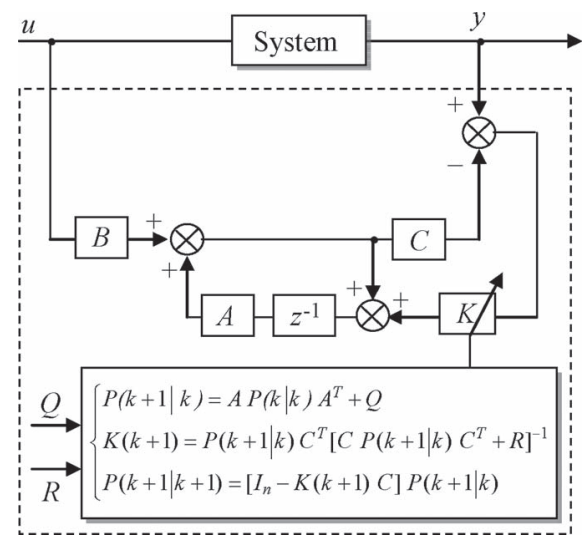

Fig. 3. Kalman filter recursive algorithm.

its extended version. Therefore, a nonlinear stochastic system discrete state equation is given by

$$
\left\{\begin{array}{l}
x_{k+1}=f\left(x_{k}, u_{k}\right)+w_{k} \\
y_{k}=h\left(x_{k}\right)+v_{k}
\end{array}\right.
$$

where $f$ and $h$ are vector functions

$$
\left\{\begin{array}{l}
f=\left[\begin{array}{l}
\left(1-T \frac{K_{R}}{K_{L}}\right) i_{s \alpha}+T \frac{L_{m} R_{r}}{L_{r}^{2} K_{1}} \lambda_{r \alpha}+T \frac{L_{m} \omega_{r}}{L_{r} K_{L}} \lambda_{r \beta}+T \frac{1}{K_{L}} V_{s \alpha} \\
\left(1-T \frac{K_{R}}{K_{L}}\right) i_{s \beta}-T \frac{L_{m} R_{r}}{L_{r}^{2} K_{L}} \lambda_{r \alpha}+T \frac{L_{m} \omega_{r}}{L_{r} K_{L}} \lambda_{r \beta}+T \frac{1}{K_{L}} V_{s \beta} \\
T \frac{L_{m}}{T_{r}} i_{s \alpha}+\left(1-T \frac{1}{T_{r}}\right) \lambda_{r \alpha}-T \omega_{r} \lambda_{r \beta} \\
T \frac{L_{m}}{T_{r}} i_{s \beta}+T \omega_{r} \lambda_{r \alpha}+\left(1-T \frac{1}{T_{r}}\right) \lambda_{r \beta} \\
\omega_{r}
\end{array}\right. \\
h=C_{d} x_{k \mid k+1}=\left[\begin{array}{l}
I_{s \alpha} \\
I_{s \beta}
\end{array}\right] .
\end{array}\right.
$$

The notation $k+1$ is related to predicted values at the $(k+$ 1)th instant and is based on measurements up to the $k$ th instant. $T$ is the sampling period.

The EKF equations are similar to those of the linear Kalman filter with the difference that $A$ and $C$ matrices should replace by the Jacobians of the vector functions $f$ and $h$ at every sampling time as follows:

$$
\left\{\begin{array}{l}
A_{k}[i, j]=\left.\frac{\partial f_{i}}{\partial x_{j}}\right|_{x=\hat{x}(k \mid k)} \\
C_{k}[i, j]=\left.\frac{\partial h_{i}}{\partial x_{j}}\right|_{x=\hat{x}(k \mid k-1)} .
\end{array}\right.
$$

The covariance matrices $R_{k}$ and $Q_{k}$ are also defined at every sampling time.

For the induction-motor control, the EKF is used for the speed real-time estimation. It can also be used to estimate states and parameters using the measurements of the motor voltages and currents.

\section{B. $L O$}

The adopted flux and speed observer uses the observed system model. It calculates the stator flux and rotational speed estimated values using the motor drive measurements (stator currents and dc voltage) [29].

The induction-motor state model developed in the stationary reference frame is given as follows:

$$
\left\{\begin{array}{l}
\frac{d x}{d t}=A x+B u \\
y=C x
\end{array}\right.
$$




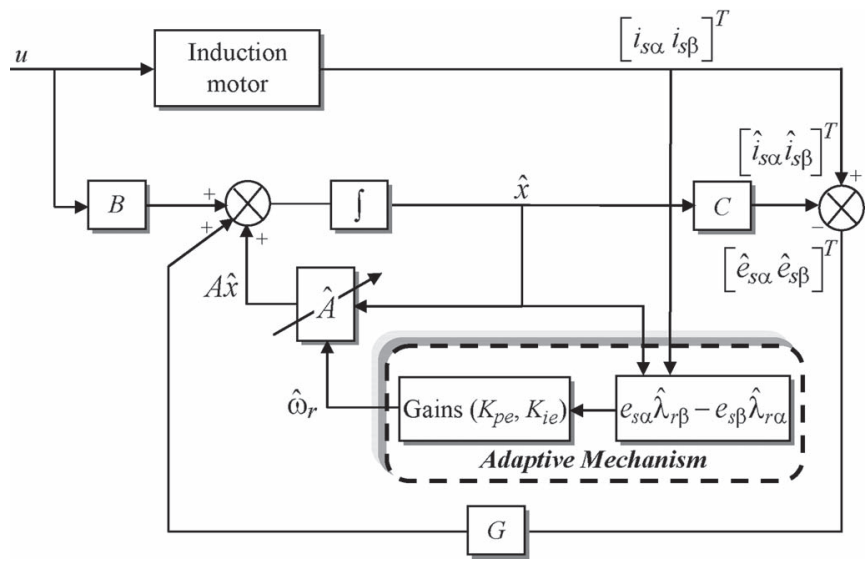

Fig. 4. Adaptive observer global structure.

where $x=\left[I_{s \alpha} I_{s \beta} \lambda_{r \alpha} \lambda_{r \beta}\right]^{T}$ is the state vector, $u=\left[V_{s \alpha} V_{s \beta}\right]^{T}$ is the input vector, and $y=\left[\begin{array}{ll}I_{s \alpha} & I_{s \beta}\end{array}\right]^{T}$ is the output vector:

$$
\left\{\begin{array}{l}
A=\left[\begin{array}{cccc}
-\frac{1}{\sigma}\left(\frac{1-\sigma}{T_{r}}+\frac{1}{T_{s}}\right) & 0 & \frac{L_{m}}{\sigma L_{s} L_{r} T_{r}} & \frac{L_{m}}{\sigma L_{s} L_{r}} \omega_{r} \\
0 & -\frac{1}{\sigma}\left(\frac{1-\sigma}{T_{r}}+\frac{1}{T_{s}}\right) & -\frac{L_{m}}{\sigma L_{s} L_{r}} \omega_{r} & \frac{L_{m}}{\sigma L_{s} L_{r} T_{r}} \\
\frac{L_{m}}{T_{r}} & 0 & -\frac{1}{T_{r}} & -\omega_{r} \\
0 & \frac{L_{m}}{T_{r}} & \omega_{r} & -\frac{1}{T_{r}}
\end{array}\right] \\
B=\left[\begin{array}{cc}
\frac{1}{\sigma L_{s}} & 0 \\
0 & \frac{1}{\sigma L_{s}} \\
0 & 0 \\
0 & 0
\end{array}\right], C=\left[\begin{array}{llll}
1 & 0 & 0 & 0 \\
0 & 1 & 0 & 0
\end{array}\right] .
\end{array}\right.
$$

The estimated speed $\omega_{r}$ is considered to be a variable parameter. Using (10), a global observer structure can be written as

$$
\frac{d \hat{x}}{d t}=\hat{A} \hat{x}+B u+G(y-\hat{y})
$$

where $G$ is the observer gain matrix, which is selected to insure the error stability. The global adaptive flux and speed observer structure is shown in Fig. 4.

The stability analysis (Lyapunov stability theorem) in terms of observation error allows having an asymptotic observer. The speed adaptive mechanism is then given by

$\hat{\omega}_{r}=K_{p e}\left(e_{s \alpha} \hat{\lambda}_{r \beta}-e_{s \beta} \hat{\lambda}_{r \alpha}\right)+K_{i e} \int\left(e_{s \alpha} \hat{\lambda}_{r \beta}-e_{s \beta} \hat{\lambda}_{r \alpha}\right) d t$

where $K_{p e}$ and $K_{i e}$ are positive gains, $e_{s \alpha}=I_{s \alpha}-\hat{I}_{s \alpha}$, and $e_{s \beta}=I_{s \beta}-\hat{I}_{s \beta}$.

The LO is based on the system equations, without taking into account the measurement noise and the disturbances. This observer is then sensitive to parameter variations, particularly at low speeds. This drawback will be therefore taken into account for the speed range application of the LO. This observer, however, has the important advantage of being less time-consuming.

\section{Speed Sensor Fault-Tolerant Control}

The overall performance of the induction-motor-based EV propulsion with a feedback structure depends on the performance of the driving circuits and sensors: speed, voltage, and current sensors [30]. The loss of a sensor leads to unsatisfactory or dangerous behaviors if no remedial actions have been forecast.

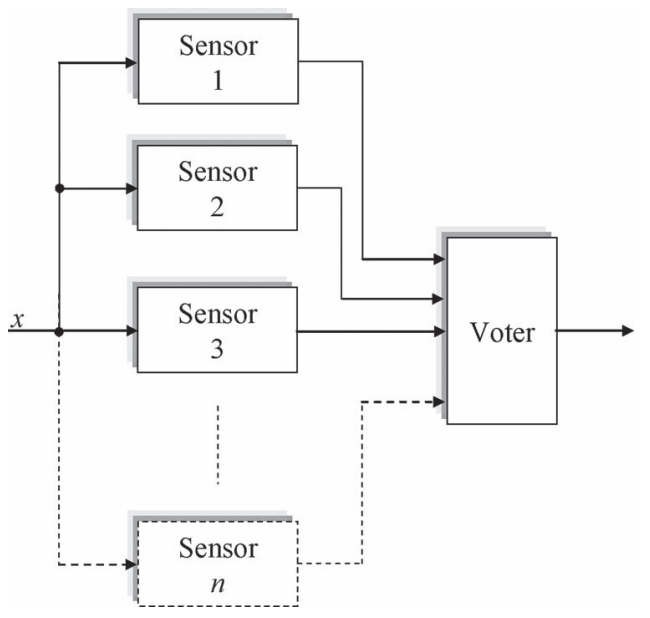

Fig. 5. Static redundancy.

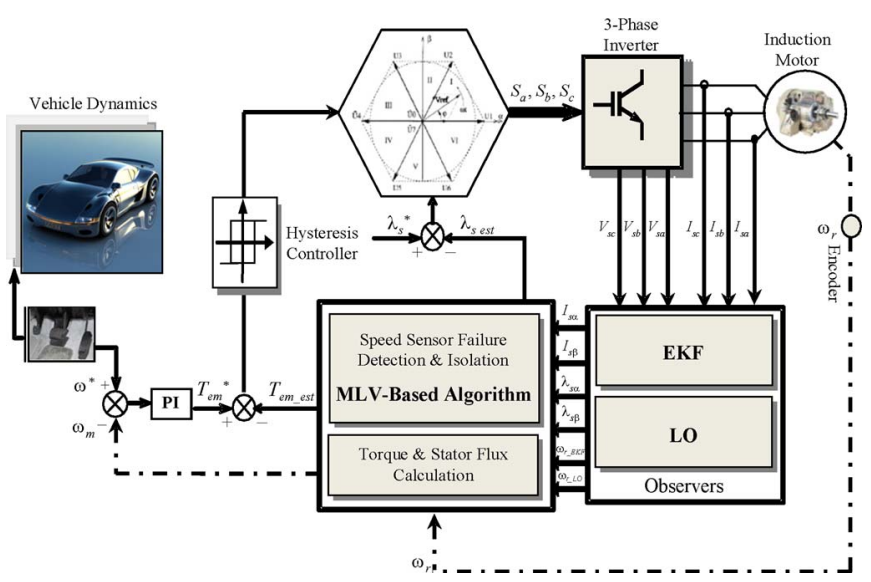

Fig. 6. Proposed sensor FTC scheme.

\section{A. Proposed FTC Philosophy}

Reconfiguration is the most comprehensive remedial action against a given failure. It generally exploits redundancy inherent in the process. The use of an analytical redundancy (called virtual sensor in our case) allows the reconstruction of the faulty sensor measurement using an analytical model of the system and measurements from other still-healthy sensors [2].

The simplest approach to achieve redundancy is the static approach. Typically, three or more sensors are used in parallel and in case of failure; a voter is used to consolidate the information. In practice, to withstand $n$ sensor failures, a total of $2 n+1$ real and virtual sensors are needed for voting (see Fig. 5). In other words, $2 n+1$ modules are required to tolerate $n$ sensor failures [2].

Fig. 6 describes the proposed sensor FTC approach. In the event of speed sensor failures, the proposed strategy reorganizes itself by using the estimated speed given by the MLV algorithm in the entire speed range. In this paper, the focus is on speed sensor failures, but the proposed FTC approach is also able to handle current and voltage sensor failures [15].

The EKF and LOs have also been adopted to optimize the FTC performances in the entire speed range. Indeed, the EKF is well adapted for low and medium speeds, whereas the LO will be adopted for high speeds. 


\section{B. On Speed Sensor Failures}

In general, a 12-bit absolute encoder can exhibit the following failure conditions: 1) intermittent sensor connection; 2) complete sensor outage; 3) DC bias in sensor measurement; and 4) sensor gain drop.

The most severe failures are the two first failures as they lead to momentary or complete lack of information. This will obviously lead to instabilities in closed-loop control if no remedial actions are undertaken [3], [6].

\section{MLV Algorithm}

To increase the drive reliability, the proposed speed sensor FTC strategy uses a voting algorithm in the control decision block that computes the most accurate speed information for DTC.

The static redundancy approach requires a voter to determine the final output speed of the EV propulsion. In this context, an in-depth overview on voting algorithms is provided in [31]. It appears then that the inexact majority and the weighted average voters are widely used in control and safety-critical applications [32]. These two voters, however, suffer from two main drawbacks: An inexact majority voter requires an appropriate threshold value, which directly affects the voter performance. A weighted average voter suffers from a lack of accuracy in healthy (normal) conditions. Indeed, the real measure is mixed with the observed measures, leading to less-accurate values [6].

The main task of the voting algorithm is to detect and reconfigure the induction-motor control in the event of a speed sensor failure using two virtual speeds, i.e., the EKF and the LOs, and the speed sensor. This voting algorithm is also used to improve the $\mathrm{EV}$ powertrain control in the entire speed range, using the appropriate estimator (EKF or LO). Based on [31], it appears that the MLV algorithm is the best candidate [19]. The MLV main idea is to choose, based on how reliable each input is and how faithful its output is, the output that is most likely correct.

In the MLV algorithm, probability $\chi_{j}$ for each input $j$ is computed based on reliability coefficients $f_{i}$ for each input as follows:

$$
\chi_{j}=\prod_{i=1}^{N} \Delta_{j}(i) / \sum_{k=1}^{N} \prod_{i=1}^{N} \Delta_{k}(i)
$$

where $N$ is the number of inputs.

In fact, the MLV algorithm uses reliability coefficients and inputs to estimate the correct output. It is based on a decreasing sequence computation and arrangement of the probability $\chi_{j}$ of each input.

In (13), where $\chi_{j}$ denominators are the same, the voter needs only to find and to compare the numerators and, thus, reduces the computation time [19]. In practice, the MLV algorithm computes $\chi_{j}$ for all the inputs $(j=1,2,3)$ and arranges them in a decreasing sequence. For a healthy speed sensor, $\chi_{j}$ has the maximum value. In this case, it is higher than those of the EKF and the LO. In the event of a speed sensor failure and if the EKF $\chi_{j}$ is higher than the $\mathrm{LO} \chi_{j}$, the EKF-based speed estimation is selected; otherwise, the LO-based speed estimation is selected.
An input gives a particular incorrect output with probability $\left(\left(1-f_{k}\right) /(N-1)\right)$. Probability coefficient computations are slightly modified to introduce a threshold $D_{\max }$. Indeed, under healthy conditions, the speed sensor is chosen as the emerging output [19] as follows:

$$
\Delta_{k}(i)= \begin{cases}f_{k}, & \text { if }\left|x_{i}-x_{k}\right| \leq D_{\max i k} \\ \frac{1-f_{k}}{N-1}, & \text { else. }\end{cases}
$$

In practice, where $x$ is the induction-motor speed and $x_{i}-x_{k}$ the speed residuals, $\Delta_{k}(i)$ and speed errors are evaluated (for $k$ and $i=1$ to 3 ) to select the probability coefficient maximum values and, therefore, to choose the correct output.

In (14), each input (in our case, the three speeds: sensor, EKF, and LO) is associated with a probability level presented by reliability coefficients. At each sample time, the MLV algorithm calculates the reliability degree of each input and affects, to the output, the input having the probability highest rate. However, a difficult task is to compute the threshold $D_{\max }$. This should be done using extensive simulations.

In (14), $D_{\max }$ represents the admissible threshold for the error between the speeds obtained by the absolute encoder, EKF, and LO. In [19], $D_{\max }$ is set to zero, i.e.,

$$
\Delta_{k}(i)= \begin{cases}f_{i}, & x_{i}=x_{k} \\ \frac{1-f_{k}}{N-1}, & \text { else. }\end{cases}
$$

In practice, the equality $x_{i}=x_{k}$ is quasi-impossible to satisfy. The MLV algorithm has, therefore, been modified by the introduction of an admissible threshold $D_{\max i k}$ between measurements. This threshold is afterward adjusted due to the used speed observers' knowledge.

To obtain the reliability coefficients and the admissible threshold of the information on the three speeds under both healthy and faulty conditions (in the particular case of an EV using normalized driving cycles), a robustness study has been carried out. Indeed, in practice, the induction-motor rotor resistance increases due to temperature increase. In this context, the robustness study is performed versus a variation of the rotor resistance. From extensive simulations, the following conclusions are achieved.

- In faulty conditions, it is found that LO has better performance for high speeds and is also less sensitive to rotor resistance variations. However, for low speeds, LO becomes more sensitive to rotor resistance variation. For high speeds and in event of fault, the adaptive observer will be adopted and will have a higher reliability coefficient.

- The EKF presents promising results for low speeds. For this reason, its reliability coefficient is higher than the LO one. The EKF will be adopted in faulty condition is this speed operating range.

- In healthy conditions, it is assumed that the speed sensor has the higher reliability coefficient in the entire speed range.

\section{Simulation Tests}

To evaluate the proposed fault-tolerant DTC strategy performance, simulations have been carried out on an EV using a $37-\mathrm{kW}$ induction-motor-based powertrain. The EV and the used cage induction-motor rated data and parameters are given in the Appendix. 


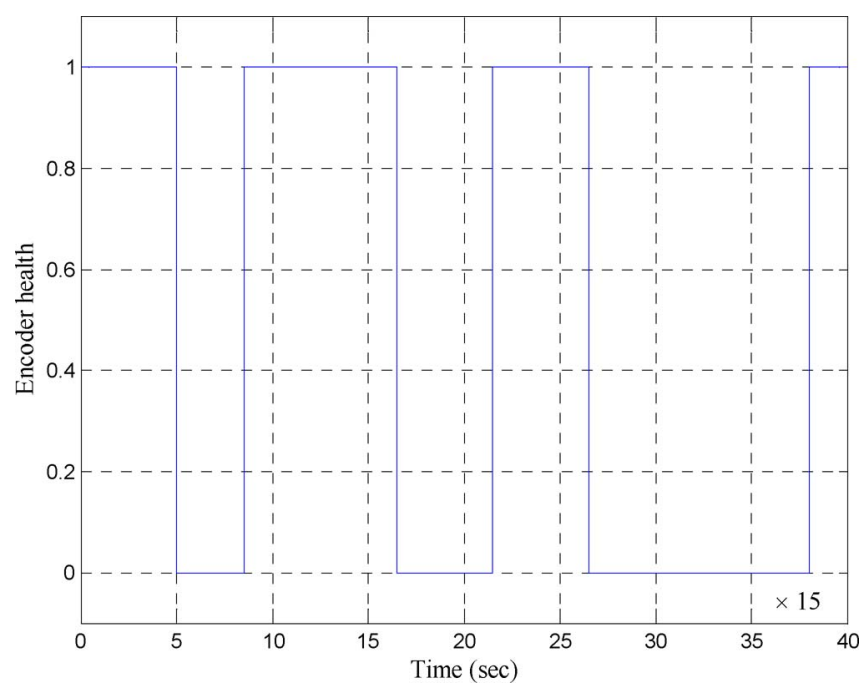

Fig. 7. Speed sensor simulated failures and recovery.

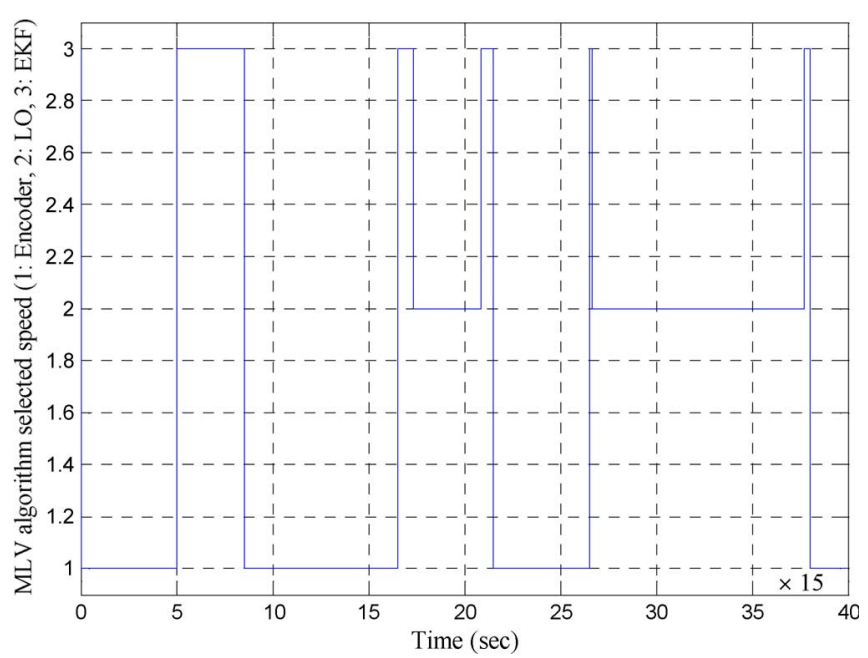

Fig. 8. MLV algorithm speed selection.

In this case, a speed sensor failure (power failure) and recovery is introduced between $5 \rightarrow 8.5,17 \rightarrow 23$, and $26.5 \rightarrow$ $38 \mathrm{~s}$ (see Fig. 7).

\section{A. MLV Algorithm Parameterization}

For parameterization purposes, extensive simulations have been carried out to compute the threshold $D_{\max }$ and the EKF and LO reliability coefficients. Therefore, we have the following.

- $D_{\max }$ has been set to $0.2 \mathrm{rad}$ at low speed and to $0.25 \mathrm{rad}$ at high speed.

- The EKF reliability coefficients have been set to 0.98 at low speed and to 0.93 at high speed.

- The LO reliability coefficients have been set to 0.93 at low speed and to 0.96 at high speed.

- The speed sensor has a constant reliability of 0.99 .

Fig. 7 shows the adopted speed sensor failures and recovery scheme. This scheme will allow testing the MLV algorithm in all the speed range (from low to high speed). Adopting this scheme, Fig. 8 shows how the given parameterized MLV algorithm selects the appropriate speed. In this context, the MLV output is set to 1 in the case of a healthy speed sensor. If the out-

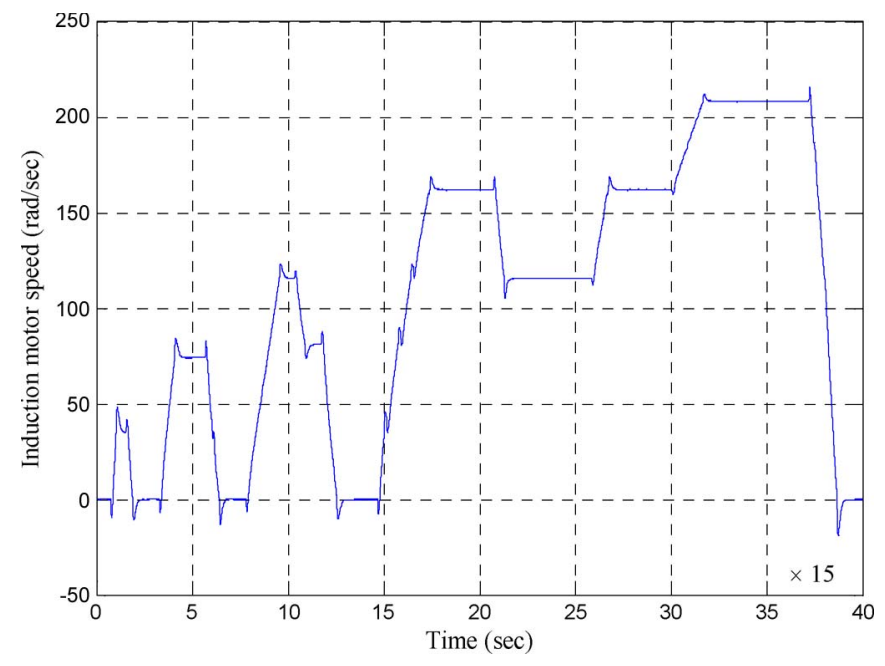

Fig. 9. EV induction-motor speed (ECE + URL).

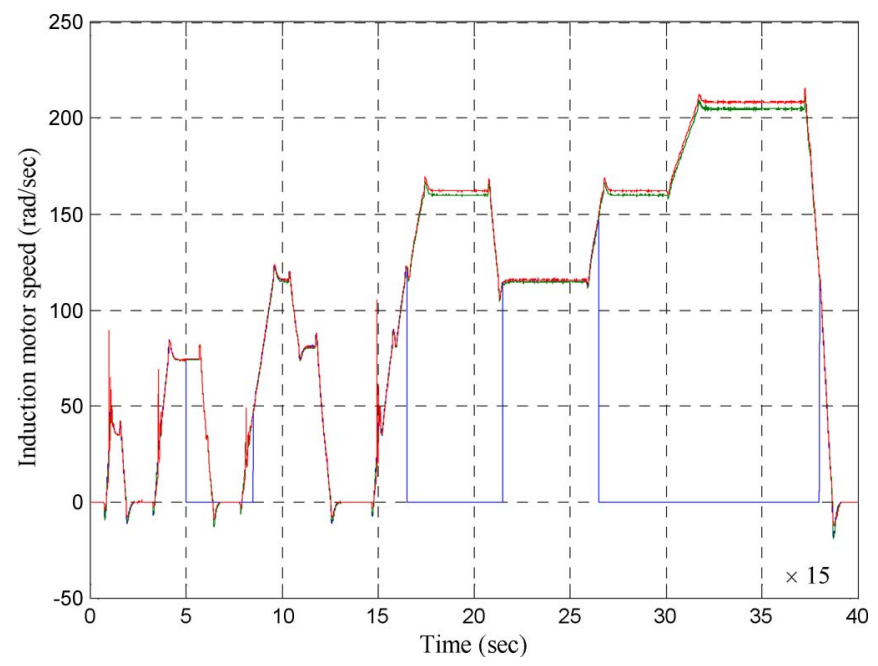

Fig. 10. EV FTC performances with MLV. (blue) Speed sensor. (green) EKF. (red) LO.

put is set to 2, the adaptive observer is selected for control purposes. Otherwise, if the output is set to 3, the EKF is preferred.

\section{B. EV Dynamic Performances Under Speed Sensor Failure}

To evaluate the EV dynamic performances under speed sensor failure and recovery, a series of tests under different load conditions was performed to emulate different types of traction behavior.

For that purpose, a European urban and extraurban driving cycle (ECE + URL) is used as the speed reference (see Fig. 9). Fig. 9 shows the induction-motor speed. The EV vehicle speed can be obtained through gear ration and wheel radius. In the entire speed range, the MLV algorithm provides the appropriate speed to the DTC to maintain the EV best achievable performances.

The EV speed and torque performances are shown in Figs. 10 and 11. Fig. 10 shows that the EKF output is selected in the case of a speed sensor failure at low and medium speeds. Indeed, in this speed range, the LO exhibits degraded performances (red). At high speed, an error is observed between the estimated speeds. In this context, the LO output is selected in the case of a 


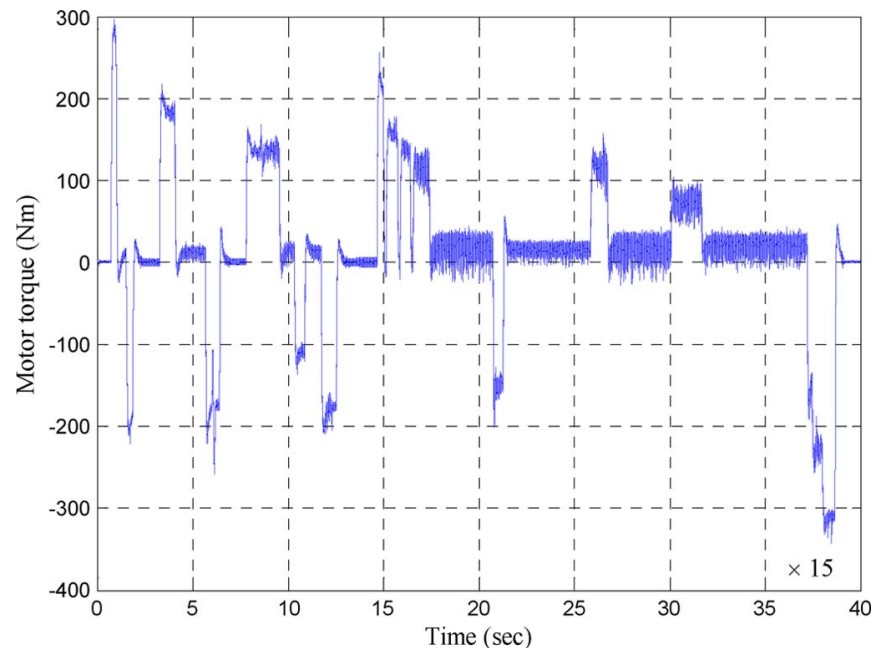

Fig. 11. EV induction-motor torque under speed sensor failures and recovery.
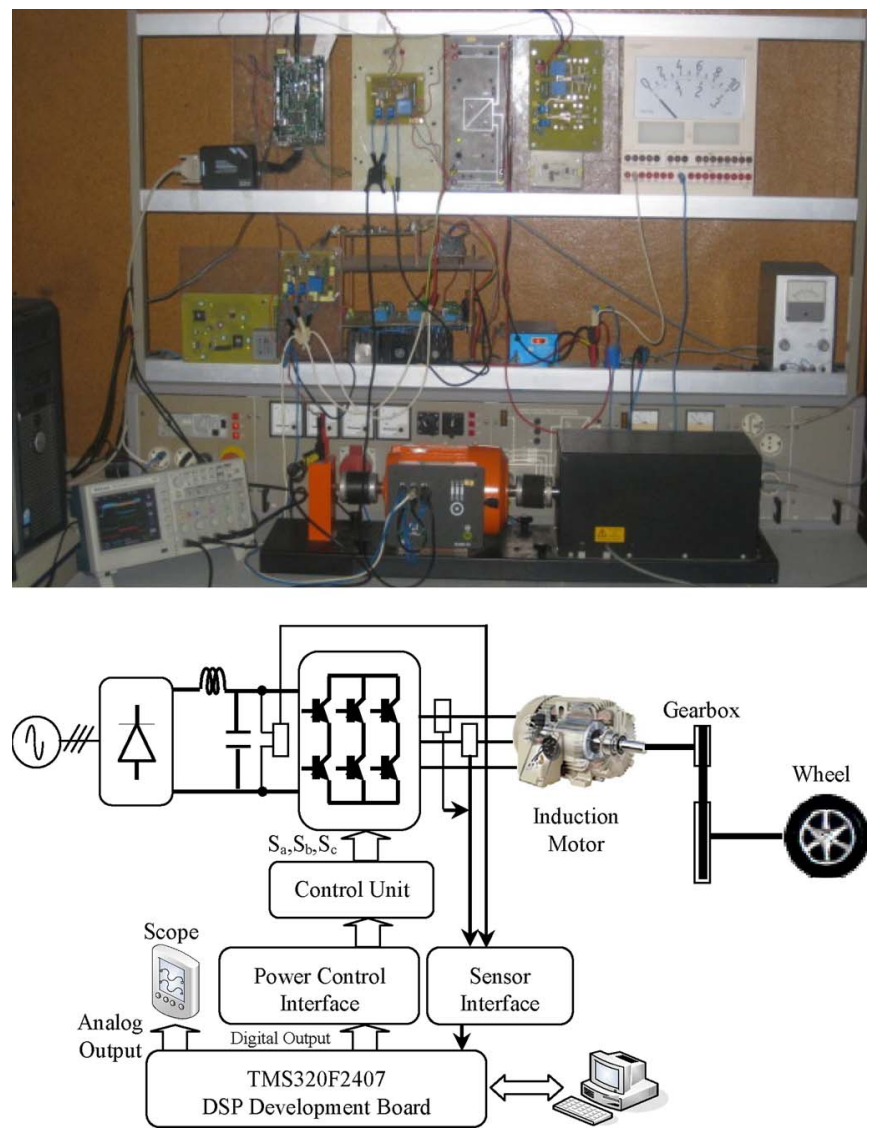

Fig. 12. View and schematic description of the experimental setup.

speed sensor failure to maintain the EV dynamic performances in the entire speed range. Fig. 11 shows that the EV induction motor torque is as large as that of the variations of the accelerator pedal and that of the road profile: It is not affected by the speed sensor failures and recovery.

\section{EXPERIMENTAL TESTS}

Experimental tests have been first carried out to check the sensor FTC performances on a $1-\mathrm{kW}$ induction-motor drive. A modified European urban driving cycle (ECE) has been also adopted.

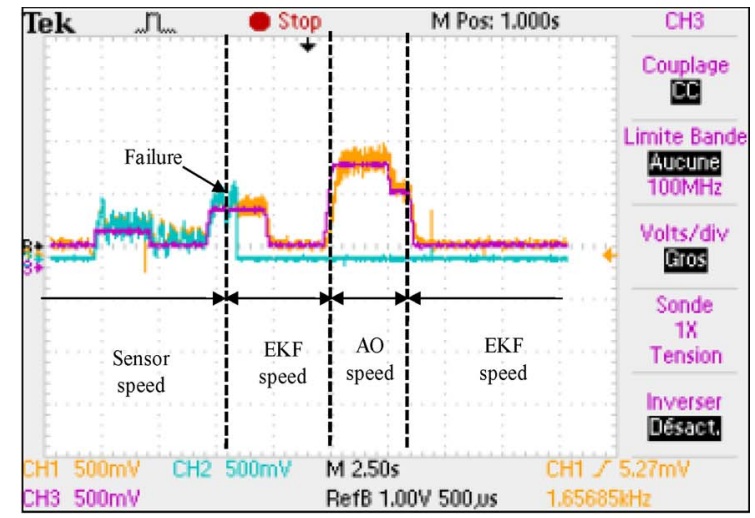

(a)

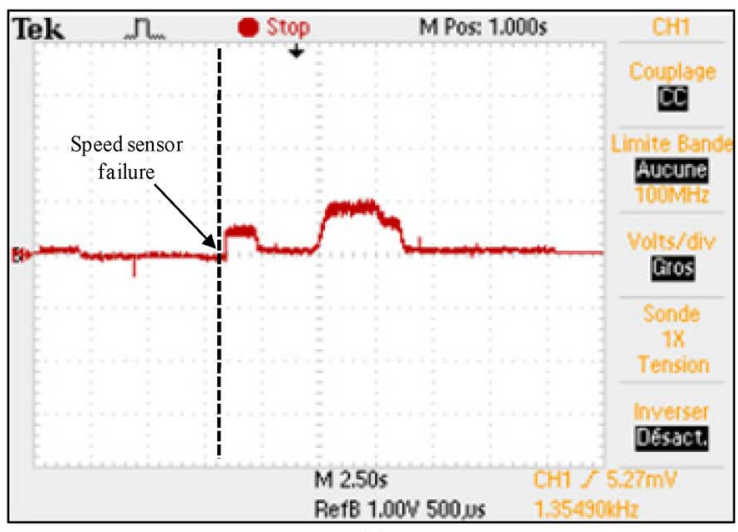

(b)

Fig. 13. Induction-motor-drive MLV_based FTC performances under speed sensor failures and recovery. (a) (Orange) Motor speed, (blue) speed sensor, and (purple) reference speed. (b) Speed residual.

\section{A. Experimental Setup}

The experimental setup picture is shown in Fig. 12. The used cage induction-motor rated data are given in the Appendix. This motor is supplied by a two-level voltage inverter. The setup main components are a digital signal processing (DSP) system (single fixed-point TMS320LF2407), a speed sensor attached to the motor shaft, and current and voltage sensors. The DSP system is interfaced to a standard PC.

\section{B. Experimental Results}

Adopting a normal European urban driving cycle, Fig. 13 shows the MLV-based FTC dynamic performances.

In this case, the MLV algorithm adopts the speed sensor output; at low speed, it adopts the EKF estimates (in case of failure), and at high speed, it adopts the LO estimates (in case of failure).

The obtained experimental results clearly confirm the effectiveness of the proposed FTC strategy using a specific voting algorithm.

\section{CONCLUSION}

This paper has proposed a fault-tolerant DTC strategy in case of speed sensor failure intended for EVs using an inductionmotor-based powertrain. For that purpose, the MLV algorithm in the control decision block that computes the most accurate 


\section{TABLE I}

\section{EV MECHANICAL AND AERODYNAMIC PARAMETERS}

$m=1540 \mathrm{~kg}$ (two $70 \mathrm{~kg}$ passengers), $A=1.8 \mathrm{~m}^{2}, r=0.3 \mathrm{~m}$

$\mu_{r r 1}=0.0055, \mu_{r r 2}=0.056, C_{a d}=0.19, G=3.29, \eta_{g}=0.95$ $v_{0}=4.155 \mathrm{~m} / \mathrm{sec}, g=9.81 \mathrm{~m} / \mathrm{sec}^{2}, \rho=0.23 \mathrm{~kg} / \mathrm{m}^{3}$

RATED DATA OF THE SiMULATED INDUCTION MOTOR

\begin{tabular}{c}
$37 \mathrm{~kW}, 1480 \mathrm{rpm}, p=2$ \\
$R_{S}=0.0851 \Omega, R_{r}=0.0658 \Omega$ \\
$L_{S}=0.0314 \mathrm{H}, L_{r}=0.0291 \mathrm{H}, L_{m}=0.0291 \mathrm{H}$, \\
$J=0.37 \mathrm{~kg} . \mathrm{m}^{2}, k_{f}=0.02791 \mathrm{Nmsec}$ \\
\hline
\end{tabular}

RATED DATA OF THE TESTED INDUCTION MOTOR

$1 \mathrm{~kW}, 2.5 \mathrm{Nm}, 2830 \mathrm{rpm}, p=1$
$R_{s}=4.750 \Omega, R_{r}=8.000 \Omega, L_{s}=0.375 \mathrm{H}, L_{r}=0.375 \mathrm{H}, L_{m}=0.364 \mathrm{H}$
$J=0.003 \mathrm{~kg} . \mathrm{m}^{2}, k_{f}=0.0024 \mathrm{Nmsec}$

speed information from the speed sensor and two virtual sensors (an EKF and a LO) has been used. The carried-out simulations and experiments on a European urban and extraurban driving cycle have shown that the proposed speed sensor FTC strategy is effective and provides a simple configuration with high dynamic performances.

\section{APPENDIX}

See Table I, which shows the electric vehicle mechanical/ aerodynamic parameters and the simulated/tested induction motors rated data.

\section{REFERENCES}

[1] A. M. El-Refaie, "Fault-tolerant permanent magnet machines: A review," IET Power Appl., vol. 5, no. 1, pp. 59-74, Jan. 2011.

[2] M. Muenchhof, M. Beck, and R. Isermann, "Fault-tolerant actuators and drives-Structures, fault detection principles and applications," Апnи. Rev. Control, vol. 33, no. 2, pp. 136-148, Dec. 2009.

[3] D. U. Campos-Delgado, D. R. Espinoza-Trejo, and E. Palacios, "Faulttolerant control in variable speed drives: A survey," IET Elect. Power Appl., vol. 2, no. 2, pp. 121-134, Mar. 2008.

[4] A. Sayed-Ahmed, B. Mirafzal, and N. A. O. Demerdash, "Fault-tolerant technique for $\Delta$-connected AC-motor drives," IEEE Trans. Energy Convers., vol. 26, no. 2, pp. 646-653, Jun. 2011.

[5] W. Zhao, M. Cheng, W. Hua, H. Jia, and R. Cao, "Back-EMF harmonic analysis and fault-tolerant control of flux-switching permanent-magnet machine with redundancy," IEEE Trans. Ind. Electron., vol. 58, no. 5, pp. 1926-1935, May 2011.

[6] A. Akrad, M. Hilairet, and D. Diallo, "Design of a fault-tolerant controller based on observers for a PMSM drive," IEEE Trans. Ind. Electron., vol. 58, no. 4, pp. 1416-1427, Apr. 2011.

[7] F. Aghili, "Fault-tolerant torque control of BLDC motors," IEEE Trans. Power Electron., vol. 26, no. 2, pp. 355-363, Feb. 2011.

[8] M. E. Romero, M. M. Seron, and J. A. De Dona, "Sensor fault-tolerant vector control of induction motors," IET Control Theory Appl., vol. 4, no. 9, pp. 1707-1724, Sep. 2010.

[9] K. Rothenhagen and F. W. Fuchs, "Doubly fed induction generator modelbased sensor fault detection and control loop reconfiguration," IEEE Trans. Ind. Electron., vol. 56, no. 10, pp. 4229-4238, Oct. 2009.

[10] K. Rothenhagen and F. W. Fuchs, "Current sensor fault detection, isolation, and reconfiguration for doubly fed induction generators," IEEE Trans. Ind. Electron., vol. 56, no. 10, pp. 4239-4245, Oct. 2009.

[11] R. Wang and J. Wang, "Fault-tolerant control with active fault diagnosis for four-wheel independently driven electric ground vehicles," IEEE Trans. Veh. Technol., vol. 60, no. 9, pp. 4276-4287, Nov. 2011.
[12] J. H. Hu, D. Yin, and Y. Hori, "Fault-tolerant traction control of electric vehicles," Control Eng. Pract., vol. 19, no. 2, pp. 204-213, Feb. 2011.

[13] M. E. H. Benbouzid, D. Diallo, and M. Zeraoulia, "Advanced faulttolerant control of induction-motor drives for EV/HEV traction applications: From conventional to modern and intelligent control techniques," IEEE Trans. Veh. Technol., vol. 56, no. 2, pp. 519-528, Mar. 2007.

[14] D. Diallo, M. E. H. Benbouzid, and A. Makouf, "A fault-tolerant control architecture for induction motor drives in automotive applications," IEEE Trans. Veh. Technol., vol. 53, no. 6, pp. 1847-1855, Nov. 2004.

[15] B. Tabbache, M. E. H. Benbouzid, A. Kheloui, and J. M. Bourgeot, "Sensor fault-tolerant control of an induction motor based electric vehicle," in Proc. ECCE EPE, Birmingham, U.K., Sep. 2011, pp. 1-8.

[16] K. S. Lee and J. S. Ryu, "Instrument fault detection and compensation scheme for direct torque controlled induction motor drives," Proc. Inst. Elect. Eng.-Control Theory Appl., vol. 150, no. 4, pp. 376-382, Jul. 2003

[17] S. Karimi, A. Gaillard, P. Poure, and S. Saadate, "Current sensor faulttolerant control for WECS with DFIG," IEEE Trans. Ind. Electron., vol. 56, no. 11, pp. 4660-4670, Nov. 2009.

[18] B. Tabbache, M. E. H. Benbouzid, A. Kheloui, and J. M. Bourgeot, "DSPbased sensor fault-tolerant control of electric vehicle powertrains," in Proc. IEEE ISIE, Gdansk, Poland, Jun. 2011, pp. 2085-2090.

[19] Y. Leung, "Maximum likelihood voting for fault-tolerant software with finite output-space," IEEE Trans. Rel., vol. 14, no. 3, pp. 419-427, Sep. 1995.

[20] B. Tabbache, A. Kheloui, and M. E. H. Benbouzid, "Design and control of the induction motor propulsion of an electric vehicle," in Proc. IEEE $V P P C$, Lille, France, Sep. 2010, pp. 1-6.

[21] A. Haddoun, M. E. H. Benbouzid, and D. Diallo, "A loss-minimization DTC scheme for EV induction motors," IEEE Trans. Veh. Technol., vol. 56, no. 1, pp. 81-88, Jan. 2007.

[22] H. U. Rehman and L. Xu, "Alternative energy vehicles drive system: Control, flux and torque estimation, and efficiency optimization," IEEE Trans. Veh. Technol., vol. 60, no. 8, pp. 3625-3634, Oct. 2011.

[23] J. Guzinski, H. Abu-Rub, M. Diguet, Z. Krzeminski, and A. Lewicki, "Speed and load torque observer application in high-speed train electric drive," IEEE Trans. Ind. Electron., vol. 57, no. 2, pp. 565-574, Feb. 2010.

[24] M. Hajian, J. Soltani, G. A. Markadeh, and S. Hosseinnia, "Adaptive nonlinear direct torque control of sensorless IM drives with efficiency optimization," IEEE Trans. Ind. Electron., vol. 57, no. 3, pp. 975-985, Mar. 2010.

[25] H. K. Khalil, E. G. Strangas, and S. Jurkovic, "Speed observer and reduced nonlinear model for sensorless control of induction motors," IEEE Trans. Control Syst. Technol., vol. 17, no. 2, pp. 327-339, Mar. 2009.

[26] M. H. Kim, S. Lee, and K. C. Lee, "Kalman predictive redundancy system for fault tolerance of safety-critical systems," IEEE Trans. Ind. Informat., vol. 6, no. 1, pp. 46-53, Feb. 2010.

[27] L. Harnefors, "Instability phenomena and remedies in sensorless indirect field oriented control," IEEE Trans. Power Electron., vol. 15, no. 4, pp. 733-743, Jul. 2002.

[28] B. Akýn, U. Orguner, A. Ersak, and M. Ehsani, "Simple derivative-free nonlinear state observer for sensorless AC drives," IEEE/ASME Trans. Mechatron., vol. 11, no. 5, pp. 634-643, Oct. 2006.

[29] B. Tabbache, A. Kheloui, and M. E. H. Benbouzid, "An adaptive electric differential for electric vehicles motion stabilization," IEEE Trans. Veh. Technol., vol. 60, no. 1, pp. 104-110, Jan. 2011.

[30] F. Gustafsson, "Rotational speed sensors: Limitations, pre-processing and automotive applications," IEEE Instrum. Meas. Mag., vol. 13, no. 2, pp. 16-23, Apr. 2010.

[31] B. Parhami, "Voting algorithms," IEEE Trans. Rel., vol. 43, no. 4, pp. 617-629, Dec. 1994.

[32] R. W. Dabney, L. Etzkorn, and G. W. Cox, "A fault-tolerant approach to test control utilizing dual-redundant processors," Adv. Eng. Softw., vol. 39, no. 5, pp. 371-383, May 2008.

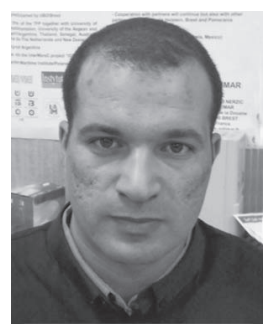

Bekheïra Tabbache was born in Chlef, Algeria, in 1979. He received the B.Sc. and M.Sc. degrees in electrical engineering from the Ecole Militaire Polytechnique, Algiers, Algeria, in 2003 and 2007, respectively. $\mathrm{He}$ is currently working toward the $\mathrm{Ph} . \mathrm{D}$. degree in electric vehicle fault-tolerant control with the University of Brest, Brest, France.

Since 2004, he has also been with the Department of Electrical Engineering, Ecole Militaire Polytechnique, as a Teaching Assistant. 


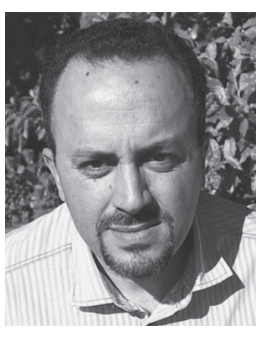

Mohamed El Hachemi Benbouzid (S'92-M'95SM'98) was born in Batna, Algeria, in 1968. He received the B.Sc. degree in electrical engineering from the University of Batna, in 1990; the M.Sc. and $\mathrm{Ph} . \mathrm{D}$. degrees in electrical and computer engineering from National Polytechnic Institute of Grenoble, Grenoble, France, in 1991 and 1994, respectively; and the Habilitation à Diriger des Recherches degree from the University of Picardie "Jules Verne," Amiens, France, in 2000.

After receiving the Ph.D. degree, he joined the Professional Institute of Amiens, University of Picardie "Jules Verne," where he was an Associate Professor of electrical and computer engineering. In September 2004, he joined the University Institute of Technology of Brest, University of Brest, Brest, France, as a Professor of electrical engineering. His main research interests include the analysis, design, and control of electric machines; variable-speed drives for traction, propulsion, and renewable energy applications; and fault diagnosis of electric machines.

Dr. Benbouzid is a Senior Member of the IEEE Power Engineering, Industrial Electronics, Industry Applications, Power Electronics, and Vehicular Technology Societies. He is an Associate Editor of the IEEE TRANSACTIONS ON ENERGY CONVERSION, THE IEEE TRANSACTIONS ON INDUSTRIAL ELECTRONICS, THE IEEE TRANSACTIONS ON VEHICULAR TECHNOLOGY, and the IEEE/ASME TRANSACTIONS ON MECHATRONICS.

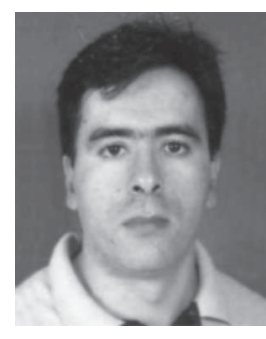

Abdelaziz Kheloui received the M.Sc. degree from Ecole Nationale d'Ingénieurs et Techniciens of Algeria, Algiers, Algeria, in 1990 and the Ph.D. degree from the National Polytechnic Institute of Lorraine, Nancy, France, in 1994, all in electrical engineering.

Since 1994, he has been with the Department of Electrical Engineering, Ecole Militaire Polytechnique, Algiers. His current research interests include the control of electrical drives and power electronics.

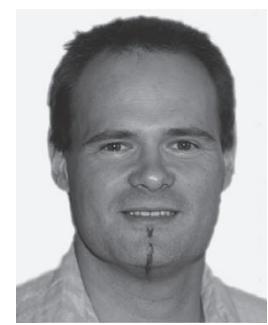

Jean-Matthieu Bourgeot was born in Grenoble, France, in 1977. He received the Ph.D. degree in control systems engineering from National Polytechnic Institute of Grenoble, in 2004.

$\mathrm{He}$ is currently an Associate Professor of control engineering with the Department of Mechatronics, Ecole Nationale d'Ingénieurs de Brest, Brest, France. His current research interests include the control and diagnosis of nonlinear systems and shape memory actuator control. 